\title{
COMPORTAMENTO DE CRISTALIZAÇÃO DE LIPÍDIOS ESTRUTURADOS POR INTERESTERIFICAÇÃO QUÍMICA DE BANHA E ÓLEO DE SOJA
}

\author{
Roberta Claro da Silva, Jonas Peixoto Escobedo e Luiz Antonio Gioielli* \\ Departamento de Tecnologia Bioquímico-Farmacêutica, Faculdade de Ciências Farmacêuticas, Universidade de São Paulo, \\ Av. Prof. Lineu Prestes, 580, 05508-900 São Paulo - SP, Brasil
}

Recebido em 21/3/07; aceito em 19/7/07; publicado na web em 23/2/08

\begin{abstract}
CRYSTALLIZATION BEHAVIOR OF STRUCTURED LIPIDS BY CHEMICAL INTERESTERIFICATION OF LARD AND SOYBEAN OIL. The aim of this study was to evaluate the crystallization behavior of binary mixtures of lard and soybean oil in different ratios and their respective structured lipids obtained by chemical interesterification. Crystallization kinetics and polarized light microscopy were used to analyze the mixtures before and after interesterification. The addition of soybean oil changed the lard crystallization, by the effect of the dilution. Crystal diameter increased, while the number of crystals decreased, as a function of temperature. Interesterification resulted in the formation of fewer crystals, with larger diameter in comparison with the original mixtures.
\end{abstract}

Keywords: crystallization; structured lipids; chemical interesterification.

\section{INTRODUÇÃO}

Lipídios estruturados podem ser definidos como triacilgliceróis reestruturados ou modificados para alterar a composição em ácidos graxos e/ou sua distribuição nas moléculas de glicerol, por métodos químicos, enzimáticos ou de engenharia genética ${ }^{1,2}$.

Os lipídios estruturados são normalmente obtidos por interesterificação. Este processo promove alteração na distribuição dos ácidos graxos nos triacilgliceróis, afetando a natureza física e o comportamento dos lipídios. A interesterificação catalisada por via química ou por lipases é utilizada na indústria de óleos e gorduras para a fabricação de margarinas e "shortenings"

A interesterificação química é uma reação ao acaso que produz completa randomização dos ácidos graxos nos triacilgliceróis ${ }^{5}$. Sob a perspectiva de custo e aplicação em larga escala, a interesterificação química parece ser o método mais atrativo. Contudo, sob a perspectiva de produzir lipídios com composições muito específicas para aplicações funcionais e medicinais, os métodos de interesterificação enzimática são mais interessantes ${ }^{6}$.

As propriedades macroscópicas de lipídios, como a espalhabilidade de margarinas e manteigas, são influenciadas particularmente pela microestrutura das gorduras. Por isso, é importante considerar os efeitos da microestrutura para posterior análise das propriedades macroscópicas? ${ }^{7}$.

O comportamento de cristalização de lipídios tem implicações importantes, principalmente no processamento industrial de produtos cujas características físicas dependem em grande parte de cristais de gordura, como chocolates, margarinas e "shortenings", assim como na separação de frações específicas a partir de gorduras naturais, através do fracionamento ${ }^{8}$. As velocidades de formação e de crescimento dos cristais e as transformações polimórficas são importantes para se determinar o processo e as condições de armazenamento de óleos e gorduras 9 .

As gorduras são polimórficas, podendo existir em três principais formas cristalinas, $\alpha, \beta$, ou $\beta$-prima e $\beta$, de acordo com a estrutura da sub-célula (secção transversal do modo de empacotamento das cadeias carbônicas). Dependendo da composição em ácidos

*e-mail: lagio@usp.br graxos dos triacilgliceróis outras formas polimórficas metaestáveis, chamadas $\gamma$ e $\delta$, e sub-formas de $\beta$ e $\beta$-prima foram observadas. As transformações de $\alpha$ para $\beta$-prima e desta para $\beta$ ocorrem nesta ordem e são irreversíveis, exceto por fusão e recristalização. Em geral, pode-se afirmar que as gorduras de composição homogênea tendem a apresentar a forma $\beta$, enquanto as de composição heterogênea tendem à forma $\beta$-prima ${ }^{10}$. Dentre as três formas polimórficas, a $\beta$ é a mais estável, $\beta$-prima é metaestável e a $\alpha$ a menos estável ${ }^{11}$. A forma $\beta$ é mais densamente empacotada, o que implica em maiores consistência e ponto de fusão ${ }^{12}$.

Durante a cristalização, o crescimento da rede sólida começa com sítios iniciais de nucleação, que crescem formando cristais maiores quando moléculas adicionais de triacilgliceróis cristalizamse. Estes cristais maiores formam elementos microestruturais de aproximadamente $10 \mu \mathrm{m}$, que então se agregam em grupos maiores, chamados de microestruturas, da ordem de $100 \mu \mathrm{m}$ ou mais. Estes grupos se empacotam de modo regular e homogêneo, formando os blocos estruturais da rede cristalina da gordura. Entre os elementos microestruturais e as microestruturas fica a fase líquida da rede (óleo) ${ }^{13}$. Quando a rede cristalina é submetida a uma tensão, as ligações entre as microestruturas têm maior probabilidade de serem rompidas que os elementos microestruturais dentro delas ${ }^{14}$.

O processo de cristalização é dividido nas fases de nucleação e crescimento dos cristais. A nucleação envolve a formação de agregados de moléculas que excederam um tamanho crítico e são, portanto, estáveis 9 . Uma vez que o núcleo cristalino se formou, este começa a crescer pela incorporação de outras moléculas, no cristal em crescimento. A velocidade de crescimento de um cristal é diretamente proporcional ao superesfriamento e inversamente proporcional à viscosidade da solução. Quanto mais alta é a viscosidade, mais difícil se torna a troca de matéria entre a fase líquida e a superfície do cristal e mais lento será seu crescimento ${ }^{4,12,15}$. Devido a interações atrativas entre os cristais, os grandes cristais que podem ser observados durante a cristalização são normalmente formados por pequenos cristais unidos por ligações fracas. A morfologia dos cristais é determinada por condições internas e externas. A cinética de cristalização de uma gordura depende da velocidade de formação do núcleo, bem como da velocidade de crescimento dos cristais. O tamanho e a forma dos cristais dependem da relação entre estes dois 
fatores. Normalmente, o resfriamento lento resulta em cristais grandes, enquanto que o resfriamento rápido produz cristais menores ${ }^{4}$.

Muitos fatores influenciam a cristalização dos lipídios, especialmente a maneira como estes são resfriados, a partir de seu estado líquido, pois quando um óleo líquido é resfriado, uma fase sólida se separa, cuja composição e quantidade dependem principalmente da velocidade de resfriamento e das temperaturas inicial e final ${ }^{15,16}$.

Os triacilgliceróis são moléculas orgânicas bem conhecidas e, portanto, os ângulos e comprimentos das ligações entre os vários átomos dentro de cada molécula são estabelecidos baseando-se na química orgânica estrutural padrão. Mesmo assim não é fácil prever a estrutura cristalina particular formada por um conjunto de moléculas de triacilgliceróis de orientação estereoespecífica conhecida. A complexidade e a flexibilidade destas moléculas também permitem diferentes empacotamentos do mesmo conjunto de moléculas, levando à existência de diferentes formas polimórficas ${ }^{17}$.

A dimensão fractal ocorre quando um objeto é classificado como sendo intermediário entre uma linha e um plano ou entre um plano e um cubo. Essa denominação decorre do fato que, ao invés desse objeto apresentar uma dimensão Euclidiana (integral), ele possui uma dimensão fracionária. Objetos fractais são muito similares entre si, por isso a geometria fractal promove boa medida desses objetos $^{18}$. Marangoni e Hartel ${ }^{19}$ estudaram a estrutura da rede cristalina de gorduras, combinando técnicas microscópicas e reológicas com a análise de fractais. Estes autores citaram que a maioria da pesquisa científica tem sido dirigida a estabelecer relações entre composição lipídica ou polimorfismo e propriedades macroscópicas de gorduras, sem considerar muito a microestrutura da rede cristalina. A não inclusão da microestrutura como uma variável importante pode levar a falhas na previsão de propriedades macroscópicas. Wright et al. ${ }^{14}$ indicaram que a dimensão fractal, determinada por reologia, da rede cristalina da gordura do leite diminuiu de 2,5 para 2,0 quando a velocidade de resfriamento da gordura foi aumentada. Isto demonstrou que maiores velocidades de resfriamento levam a decréscimo da ordem na distribuição espacial da rede microestrutural, o que resulta em menor valor para a dimensão fractal. Sistemas com maiores valores para a dimensão fractal demonstram maior ordem de empacotamento dos elementos microestruturais que aqueles com menores valores.

Marangoni e Rousseau ${ }^{20}$ afirmaram que existe a possibilidade de que não seja o conteúdo de gordura sólida e/ou a forma polimórfica do cristal que determinam as propriedades mecânicas das misturas de gordura do leite com óleo de canola, mas sim a estrutura macroscópica da rede de cristais na matriz líquida oleosa. Através do estudo das dimensões fractais e da aplicação desta teoria aos estudos de reologia das misturas de gordura do leite com óleo de canola, estes pesquisadores observaram que a dimensão fractal (D) foi o único "indicador" que variou seguindo as mudanças associadas à reologia do produto decorrentes da interesterificação. Os indicadores físicos tradicionais, como polimorfismo e conteúdo de gordura sólida, falharam em demonstrar as mudanças esperadas. Assim, ficou clara a importância da dimensão fractal, um indicador fundamental da rede cristalina que podia ser usado para explicar mudanças na reologia das gorduras não atribuídas a outras propriedades mensuráveis da rede $7,17,18,21$.

Os parâmetros de Avrami fornecem informações sobre a natureza do processo de cristalização. A constante $\mathrm{k}$ representa a velocidade de cristalização. Depende principalmente da temperatura de cristalização e esta dependência é geralmente expressa pela Equação de Arrhenius. A constante $\mathrm{k}$ leva em consideração tanto a nucleação quanto a taxa de crescimento dos cristais. $\mathrm{O}$ expoente de Avrami n, às vezes chamado de índice de cristalização, indica o mecanismo de crescimento dos cristais. Este parâmetro é uma fun- ção combinada da dependência do tempo por parte da nucleação e do número de dimensões em que o crescimento ocorre. A nucleação pode ser instantânea, com os núcleos surgindo todos de uma só vez no início do processo, ou esporádica, com o número de núcleos aumentando linearmente com o tempo. O crescimento ocorre tomando formas de agulhas, discos ou esferulitos, em uma, duas ou três dimensões, respectivamente ${ }^{22}$.

Os lipídios estruturados a partir de banha e óleo de soja têm características que possibilitam seu uso como sucedâneos da gordura do leite humano ${ }^{23}$.

Este trabalho teve por objetivo analisar a estrutura cristalina da banha em misturas binárias com óleo de soja, modificadas pelo uso da interesterificação química.

\section{PARTE EXPERIMENTAL}

A banha e o óleo de soja foram obtidos no comércio local.

As misturas foram preparadas nas seguintes proporções banha: soja (p/p): 100:0, 80:20 e 60:40, após fusão completa à temperatura de $70{ }^{\circ} \mathrm{C}$ e novamente solidificadas, sendo armazenadas sob resfriamento.

\section{Interesterificação química}

Foram interesterificados $250 \mathrm{~g}$ de amostra, previamente submetida à secagem em balão de vidro, sob pressão reduzida, acoplado a um rotaevaporador em banho de água a aproximadamente $95^{\circ} \mathrm{C}$. A essa porção foram misturados $0,5 \%(\mathrm{~m} / \mathrm{m})$ de catalisador metóxido de sódio (Merck). A reação de interesterificação foi realizada sob agitação constante, sob pressão reduzida $(20-30 \mathrm{~mm} \mathrm{Hg})$, a $70{ }^{\circ} \mathrm{C}$ em balão de três bocas imerso em banho de água a $70{ }^{\circ} \mathrm{C}$, por $1 \mathrm{~h}$. Para interromper a reação foi adicionada água destilada. Para minimizar o escurecimento decorrente da reação e para reter a umidade, respectivamente, foram adicionados sílica em pó e sulfato de sódio anidro. Os produtos foram filtrados a quente utilizando-se papel de filtro ${ }^{24-26}$.

\section{Microscopia sob luz polarizada}

As amostras foram fundidas à temperatura de $70{ }^{\circ} \mathrm{C}$ para preparação das lâminas para microscopia. As lâminas, lamínulas e tubos capilares foram pré-aquecidos em estufa a $70{ }^{\circ} \mathrm{C}$. Usando um tubo capilar, uma gota de gordura foi depositada sobre a lâmina e coberta com uma lamínula. As amostras preparadas foram mantidas à temperatura de $70{ }^{\circ} \mathrm{C}$ durante $30 \mathrm{~min}$. Foram preparadas duas lâminas de cada amostra. As lâminas foram condicionadas em estufa a 15, 20, 25 e $30{ }^{\circ} \mathrm{C}$ por $5 \mathrm{~h}$. As amostras foram observadas com aumento de 40 vezes. O microscópio de luz polarizada (Olympus) foi ligado a uma câmera de vídeo digital (Media Cybernetics). A imagem foi digitalizada pelo programa de computador Image Pro-Plus versão 4. 5. 1. 2 (Media Cybernetics). A partir das imagens vistas através do microscópio, para cada lâmina foram escolhidos quatro campos representativos. Com o software Image Pro-Plus 4. 5. 1. 2 foram determinados os diâmetros e número dos cristais e com o software Benoit 1. 3 (TruSoft International Inc. ) foi determinada a dimensão fractal das amostras, pelo método da contagem de caixas ${ }^{27-30}$.

\section{Cinética de cristalização}

A cinética de cristalização foi realizada pela determinação do conteúdo de gordura sólida por ressonância magnética nuclear (RMN), utilizando aparelho Maran Ultra Bench Top NMR, de $20 \mathrm{MHz}$. As amostras foram analisadas em duplicata. $\mathrm{O}$ seguinte tratamento térmi- 
co foi usado: as misturas já acondicionadas nos tubos de RMN foram fundidas e mantidas a $60{ }^{\circ} \mathrm{C}$ por 30 min e posteriormente colocadas em banho de água na temperatura de cristalização $\left(10^{\circ} \mathrm{C}\right)$. O conteúdo de gordura sólida foi determinado em função do tempo, até 120 min de cristalização. A Equação de Avrami original ${ }^{22}$ foi linearizada segundo a dedução a seguir e aplicada aos resultados obtidos.

$$
\begin{aligned}
& 1-\frac{C G S(t)}{C G S(\infty)}=e^{-k t^{n}} \\
& \ln \left[1-\frac{C G S(t)}{C G S(\infty)}\right]=-k t^{n} \\
& -\ln \left[1-\frac{C G S(t)}{C G S(\infty)}\right]=k t^{n} \\
& \ln \left\{-\ln \left[1-\frac{C G S(t)}{C G S(\infty)}\right]\right\}=\ln k+n \ln t
\end{aligned}
$$

onde: $\operatorname{CGS}(\mathrm{t})=$ conteúdo de gordura sólida no tempo t; $\operatorname{CGS}(\infty)=$ conteúdo de gordura sólida máximo, obtido quando a cristalização está finalizada; $\mathrm{k}=$ constante de Avrami $\left(\mathrm{min}^{-1}\right) ; \mathrm{t}=$ tempo (min); $\mathrm{n}$ $=$ expoente de Avrami.

A partir da Equação de Avrami linearizada foram calculados a constante e o expoente de Avrami ${ }^{29}$.

\section{RESULTADOS E DISCUSSÃO}

A avaliação do conteúdo de gordura sólida em função do tempo de cristalização da banha e de suas misturas com 20 e $40 \%$ de óleo de soja, antes e após a interesterificação química, permitiram a construção das curvas de cinética de cristalização a $10{ }^{\circ} \mathrm{C}$, representadas pelas Figuras 1, 2 e 3.

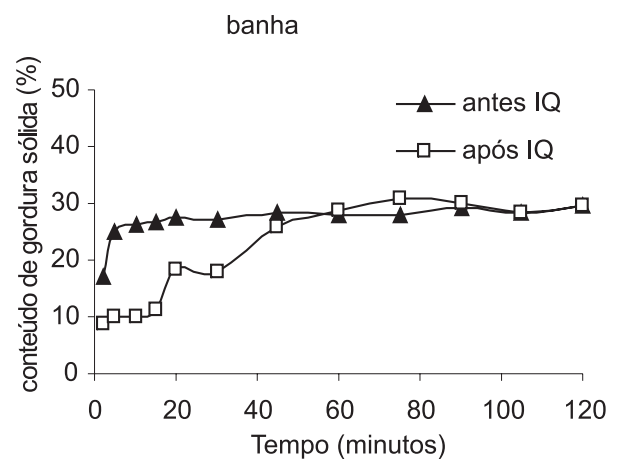

Figura 1. Cinética de cristalização a $10{ }^{\circ} \mathrm{C}$ da banha antes e após a interesterificação

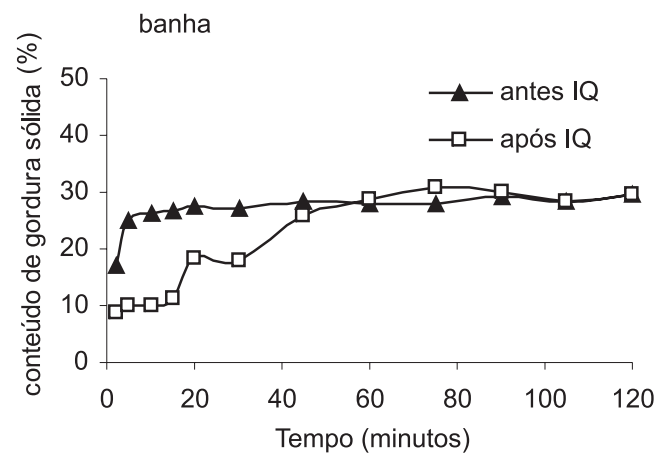

Figura 2. Cinética de cristalização a $10^{\circ} \mathrm{C}$ da mistura de banha com $20 \%$ de óleo de soja antes e após a interesterificação

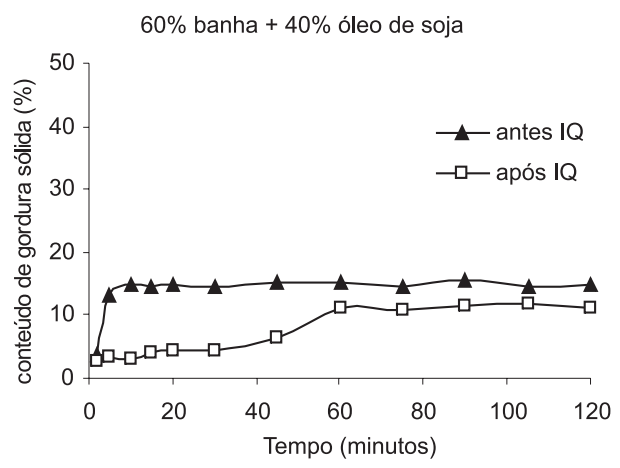

Figura 3. Cinética de cristalização a $10^{\circ} \mathrm{C}$ da mistura de banha com $40 \%$ de óleo de soja antes e após a interesterificação

A interesterificação mudou o formato da curva em todas as amostras. As curvas antes da interesterificação apresentavam formato hiperbólico, não apresentando período de indução inicial. Contudo, após a reação as amostras apresentaram formato sigmoidal característico do modelo de Avrami ${ }^{31}$, com período de indução em que a cristalização ocorre lentamente. Isto pode estar relacionado à mudança na forma polimórfica da banha, que após a interesterificação tende a cristalizar na forma $\beta$ ao invés de forma $\beta$-pri$\mathrm{ma}^{10}$.

A Tabela 1 apresenta os parâmetros de Avrami, que indicam a velocidade (k) e a forma de cristalização (n), antes e após a interesterificação.

A constante de Avrami k diminuiu com o aumento da proporção de óleo de soja na mistura, indicando que a velocidade de cristalização foi menor em função do efeito de diluição da banha com o óleo líquido. Observa-se ainda que a interesterificação promoveu queda na velocidade de cristalização das amostras.

O expoente de Avrami n, que indica o mecanismo de crescimentos dos cristais, aumentou com a adição de óleo de soja. Com exceção da mistura que continha $40 \%$ de óleo de soja, os valores de n situaram-se entre 0 e 1 , indicando crescimento em forma de agulha a partir de núcleos instantâneos. Na mistura que continha $40 \%$ de óleo de soja o valor do expoente foi superior a 1 , indicando a formação de cristais tipo agulha a partir de núcleos esporádicos ou cristais em forma de disco a partir de núcleos instantâneos ${ }^{22}$. Estas formas de cristalização são devidas à baixa temperatura empregada $\left(10^{\circ} \mathrm{C}\right)$. Portanto, a esta temperatura não foram detectadas diferenças significativas na forma de cristalização em decorrência da mistura de banha com óleo de soja ou da interesterificação, embora a velocidade

\begin{tabular}{|c|c|c|c|}
\hline & $\mathrm{k}\left(\min ^{-1}\right)$ & $\mathrm{n}$ & $\mathrm{R}^{2}$ \\
\hline & \multicolumn{3}{|c|}{ Antes da interesterificação } \\
\hline \multicolumn{4}{|c|}{ Banha:Soja } \\
\hline 100:0 & 0,84 & 0,44 & 0,85 \\
\hline $80: 20$ & 0,63 & 0,63 & 0,76 \\
\hline \multirow[t]{2}{*}{$60: 40$} & 0,14 & 1,44 & 0,46 \\
\hline & \multicolumn{3}{|c|}{ Após a interesterificação } \\
\hline \multicolumn{4}{|c|}{ Banha:Soja } \\
\hline 100:0 & 0,15 & 0,63 & 0,87 \\
\hline $80: 20$ & 0,11 & 0,64 & 0,81 \\
\hline $60: 40$ & 0,10 & 0,74 & 0,76 \\
\hline
\end{tabular}

Tabela 1. Constante de Avrami (k), expoente de Avrami (n) e coeficiente de determinação $\left(\mathrm{R}^{2}\right)$ das misturas de banha e óleo de soja antes e após a interesterificação 
de cristalização tenha diminuído após o rearranjo ao acaso.

As técnicas de análise microscópica são frequentemente as mais apropriadas para avaliar a estrutura de alimentos, visto que fornecem resultados tanto na forma de imagens como em dados numéricos. O sucesso nas medidas exige vários estágios, incluindo obter uma imagem representativa do material, analisar a imagem adequadamente e interpretar os dados resultantes ${ }^{32}$.

Quando a temperatura de cristalização está distante do ponto de fusão da amostra, ocorre formação de cristais menores e em maior número. Próximo ao ponto de fusão, a amostra apresenta pequeno conteúdo de gordura sólida e os cristais formados são pequenos e não possuem forma distinta, ou não se formam. Deste modo, uma temperatura intermediária de cristalização auxilia na formação de cristais maiores, em menor número e com formas distintas.

A Figura 4 apresenta a estrutura cristalina da banha antes e após a interesterificação química, por cristalização lenta na faixa de temperatura de 15 a $30^{\circ} \mathrm{C}$.

$\mathrm{O}$ resultado da cristalização das amostras pode ser analisado sob os pontos de vista do efeito da temperatura e da influência da presença do óleo de soja na formação da rede cristalina da banha, tanto antes quanto após a interesterificação.

Em relação à temperatura, como a velocidade de nucleação aumenta de forma exponencial com o aumento da supersaturação, enquanto a velocidade de crescimento é linearmente proporcional à supersaturação, o número de cristais aumenta e o tamanho dos cristais diminui quando a cristalização ocorre a baixas temperaturas ${ }^{11,33}$ . Isto pode ser observado na Figura 4, onde o diâmetro médio dos cristais de todas as amostras aumentou com o aumento da temperatura, atingindo valores da ordem de $200 \mu \mathrm{m}$. À temperatura de $15^{\circ} \mathrm{C}$ os cristais observados foram pequenos, da ordem de 6 a $20 \mu \mathrm{m}$, na forma de agulhas ou discos, característicos de valores do expoente $n$ de Avrami entre 1 e $3^{22}$. Os esferulitos, que apresentam valores de $n$ entre 3 e 4, somente foram observados nas temperaturas de 20 a 30 ${ }^{\circ} \mathrm{C}$. Da mesma forma, o número de cristais sempre diminuiu com o aumento da temperatura. $\mathrm{O}$ resfriamento rápido a baixa temperatura seguido de agitação intensa leva à formação de cristais pequenos, como os encontrados na margarina. Por outro lado, o resfriamento lento sob agitação suave leva à formação de cristais grandes facilmente visíveis a olho nu. Neste caso, os cristais podem formar aglomerados de esferulitos com tamanhos de centenas de micrômetros ${ }^{11,33}$, fato importante para facilitar a filtração no processo de modificação de lipídios por fracio-namento.

A banha tende a cristalizar na forma $\beta$, embora tenha uma composição em ácidos graxos heterogênea, que provocaria a cristalização na forma $\beta$-prima. Contudo, pelo fato de apresentar alta proporção de ácido palmítico na posição sn-2, a composição em triacilgliceróis pode ser considerada homogênea, o que induz à cristalização na forma $\beta^{8}$.

A tendência de cristalização da banha pode ser modificada pela interesterificação química ${ }^{34}$, passando a cristalizar-se na forma $\beta$ prima $^{8}$. A interesterificação química alterou o comportamento de cristalização da banha (Figura 4), causando decréscimo acentuado no número de esferulitos nas temperaturas de 15 e $20{ }^{\circ} \mathrm{C}$, embora não tenha sido possível observar diferenças morfológicas entre as formas $\beta$ e $\beta$-prima.

Em relação ao efeito da presença do óleo de soja na formação da rede cristalina, os resultados indicam que a tendência de cristalização da banha se mantém nas misturas, porém a cristalização é dificultada pelo efeito da diluição com óleo de soja. Assim, em cada temperatura de análise, houve tendência a aumentar o diâmetro dos cristais à medida que aumentava a participação do óleo de soja na mistura, pois a velocidade de cristalização era cada vez menor. Da mesma forma, o número de cristais apresentou tendência a dimi-
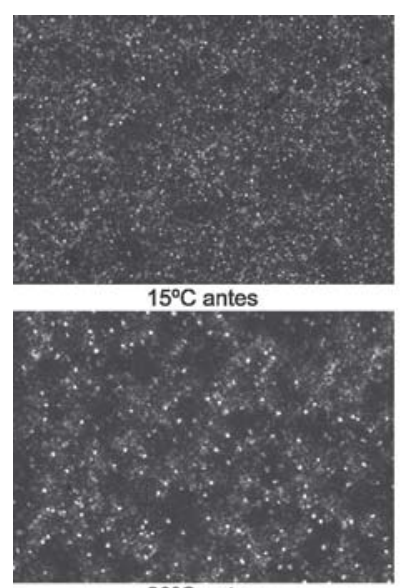

$20^{\circ} \mathrm{C}$ antes
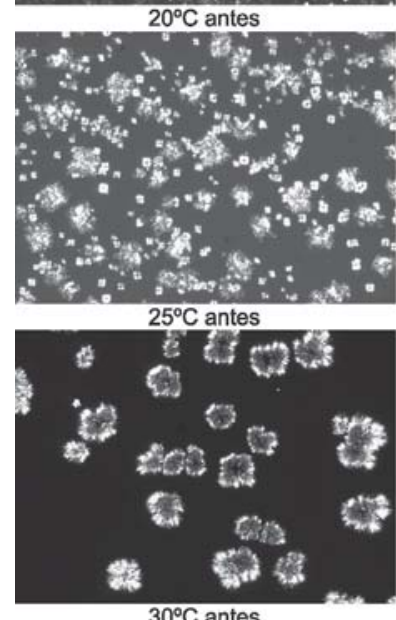

$30^{\circ} \mathrm{C}$ antes

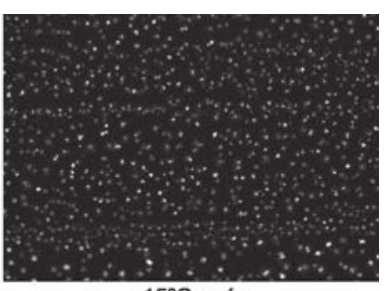

$15^{\circ} \mathrm{C}$ após

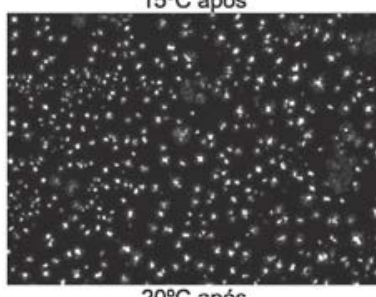

$20^{\circ} \mathrm{C}$ após
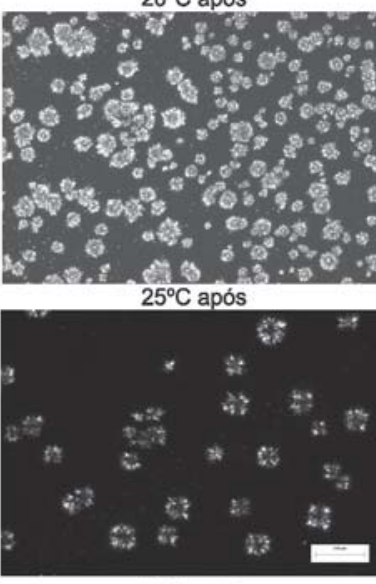

$30^{\circ} \mathrm{C}$ após
Figura 4. Imagens da cristalização da banha antes e após a interesterificação química. A barra representa $200 \mu \mathrm{m}$

nuir (Figuras 5 e 6). Enquanto a banha isoladamente apresentou estrutura cristalina a $30{ }^{\circ} \mathrm{C}$, as misturas com 20 e $40 \%$ de óleo de soja não cristalizaram a esta temperatura.

A comparação dos resultados dos diâmetros médios e do número de cristais das amostras interesterificadas com as originais mostra a alteração na estrutura cristalina provocada pelo rearranjo ao acaso. As amostras interesterificadas apresentaram tendência à formação de cristais de maior diâmetro e em menor número que as originais às temperaturas de 15 e $20{ }^{\circ} \mathrm{C}$ (Tabelas 2 e 3). Por outro lado, às temperaturas de 25 e $30^{\circ} \mathrm{C}$ os cristais tenderam a apresentar menores diâmetros que as originais. Estes efeitos podem ser decorrentes da formação em maior quantidade de triacilgliceróis trissaturados e dissaturados após a interesterificação, que apresentam maiores pontos de fusão ${ }^{23}$. Os altos valores do desvio-padrão em relação à média do diâmetro dos cristais, ou seja, altos coeficientes de variação, são característicos de gorduras cristalizadas quando observadas em microscopia sob luz polarizada ${ }^{16,31,35}$.

A Tabela 4 apresenta os resultados da dimensão fractal da banha e suas misturas binárias com óleo de soja antes e após a interesterificação química.

A dimensão fractal variou de 1,08 a 1,80. A dimensão fractal, quando determinada pelo método de caixas, depende do grau de preenchimento da estrutura cristalina e da forma dos cristais obtidos ${ }^{27}$. Assim sendo, não foi possível relacionar as diferenças observadas da dimensão fractal entre as amostras como sendo decorrentes da temperatura de cristalização ou da presença do óleo de soja. Contudo, quando a forma dos cristais é semelhante, como ocorre com as 

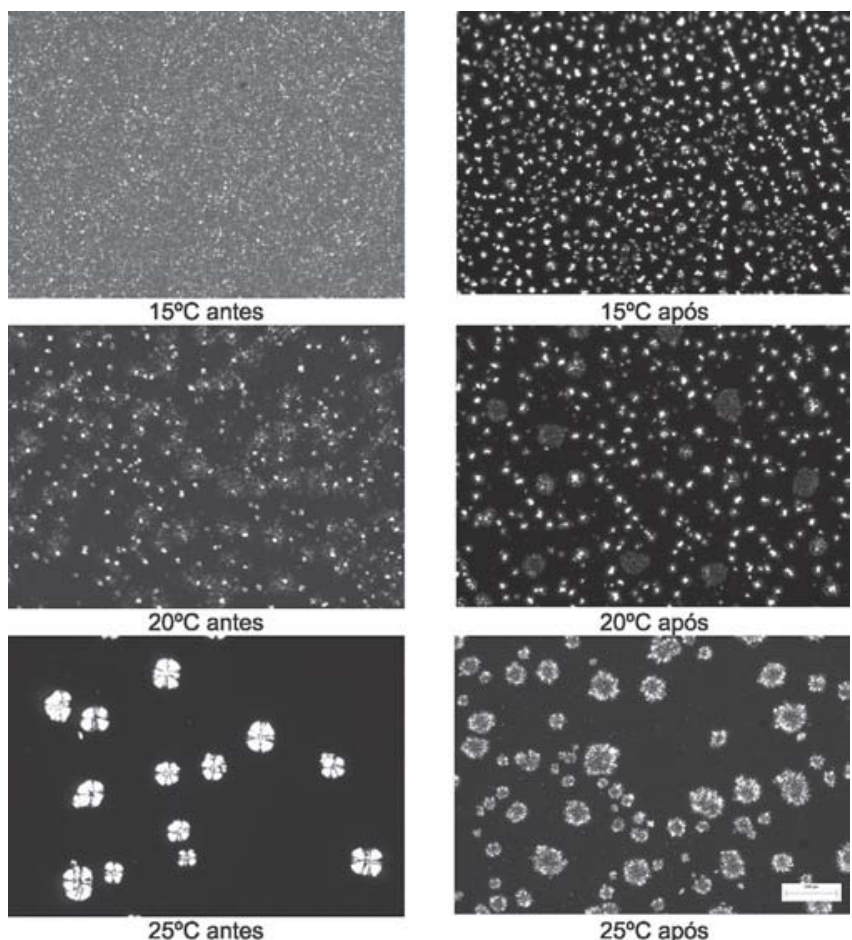

$25^{\circ} \mathrm{C}$ antes

$25^{\circ} \mathrm{C}$ após

Figura 5. Imagens da cristalização da mistura de $80 \%$ de banha com $20 \%$ de óleo de soja antes e após a interesterificação química. A barra representa $200 \mu \mathrm{m}$

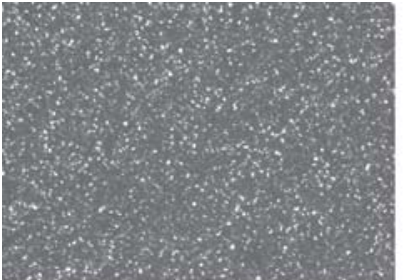

$15^{\circ} \mathrm{C}$ antes

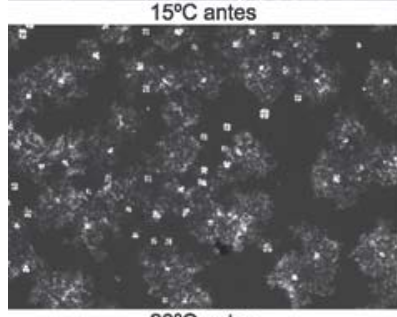

$20^{\circ} \mathrm{C}$ antes

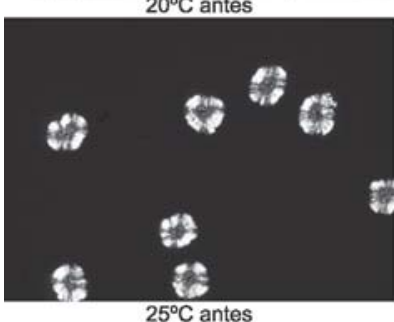

Figura 6. Imagens da cristalização da mistura de $60 \%$ de banha com $40 \%$ de óleo de soja antes e após a interesterificação química. A barra representa $200 \mu \mathrm{m}$

amostras à temperatura de $15{ }^{\circ} \mathrm{C}$, a dimensão fractal apresentou tendência a diminuir após a interesterificação, pois o grau de preenchimento da estrutura cristalina vai gradualmente se tornando menor à medida que aumenta a participação do óleo de soja na mistura
Tabela 2. Diâmetro médio dos cristais das misturas de banha e óleo de soja antes e após a interesterificação química

\begin{tabular}{|c|c|c|c|c|}
\hline \multicolumn{5}{|c|}{ Diâmetro dos cristais $(\mu \mathrm{m})$} \\
\hline & \multicolumn{4}{|c|}{ Temperatura $\left({ }^{\circ} \mathrm{C}\right)$} \\
\hline & 15 & 20 & 25 & 30 \\
\hline Banha:Soj & \multicolumn{4}{|c|}{ Antes de interesterificação } \\
\hline 100:0 & $7,31 \pm 4,15$ & $7,43 \pm 5,39$ & $45,21 \pm 25,68$ & $197,50 \pm 48,64$ \\
\hline $80: 20$ & $6,72 \pm 3,76$ & $8,94 \pm 6,54$ & $116,26 \pm 18,28$ & - \\
\hline $60: 40$ & $7,48 \pm 4,28$ & $18,47 \pm 8,03$ & $181,31 \pm 13,91$ & - \\
\hline \multicolumn{2}{|c|}{ Banha:Soja } & \multicolumn{3}{|c|}{ Após a interesterificação } \\
\hline 100:0 & $9,75 \pm 4,05$ & $13,02 \pm 6,99$ & $74,91 \pm 31,85$ & $126,09 \pm 27,04$ \\
\hline 80:20 & $20,35 \pm 6,71$ & $50,26 \pm 31,92$ & $80,58 \pm 31,86$ & - \\
\hline $60: 40$ & $17,05 \pm 6,72$ & $68,96 \pm 52,12$ & $115,29 \pm 21,96$ & - \\
\hline
\end{tabular}

Tabela 3. Número de cristais das misturas de banha e óleo de soja antes e após a interesterificação química

\begin{tabular}{|c|c|c|c|c|}
\hline \multicolumn{5}{|c|}{ Número de cristais } \\
\hline & \multicolumn{4}{|c|}{ Temperatura $\left({ }^{\circ} \mathrm{C}\right)$} \\
\hline & 15 & 20 & 25 & 30 \\
\hline Banha:Soja & \multicolumn{4}{|c|}{ Antes da interesterificação } \\
\hline 100:0 & 5877 & 1820 & 252 & 25 \\
\hline $80: 20$ & 5994 & 912 & 13 & - \\
\hline $60: 40$ & 3093 & 311 & 8 & - \\
\hline Banha:Soja & \multicolumn{4}{|c|}{ Após a interesterificação } \\
\hline 100:0 & 830 & 636 & 159 & 28 \\
\hline $80: 20$ & 671 & 306 & 74 & - \\
\hline $60: 40$ & 647 & 82 & 6 & - \\
\hline
\end{tabular}

rearranjada. A dimensão fractal da rede cristalina é uma medida da ordem na distribuição espacial da massa sólida na rede, sendo que maiores valores para a dimensão fractal representam uma distribuição mais organizada ${ }^{14}$. Assim sendo, os valores da dimensão fractal decorrente do resfriamento rápido a $15{ }^{\circ} \mathrm{C}$ apresentaram tendência a diminuir pela maior quantidade de óleo de soja na mistura rearranjada, que por ser líquido tornou menor a ordem de empacotamento dos elementos microestruturais. Por outro lado, a formação de aglomerados de cristais e esferulitos de maior diâmetro, o que foi observado às temperaturas de $20 \mathrm{e} 25^{\circ} \mathrm{C}$, provoca a variação da dimensão fractal, assim como foi observado por Marangoni ${ }^{28}$, ao estudar a dimensão fractal de óleo de palma a diversos conteúdos de gordura sólida. A dimensão fractal determinada por microscopia de diversas gorduras comestíveis varia entre 1,47 a 1,88 , estando, entre estas, a manteiga de cacau $(\mathrm{D}=1,56)$, a gordura do leite não interesterificada $(\mathrm{D}=$ $1,85)$ e a gordura de palma $(\mathrm{D}=1,87)^{7,17}$.

As alterações no diâmetro e número dos cristais, assim como na dimensão fractal das amostras interesterificadas podem estar relacionadas à alteração na forma polimórfica dos cristais de banha provocada pelo rearranjo ao acaso, que passam da forma $\beta$ para $\beta$-prima, pois a composição em triacilgliceróis após o rearranjo tende a ser heterogênea, com menor participação do ácido palmítico na posição sn-2. Isto melhora a plasticidade dos produtos que utilizam a banha modificada, ocasionando resultados superiores na panificação e na aparência durante o armazenamento ${ }^{8}$. 
Tabela 4. Dimensão fractal dos cristais das misturas de banha e óleo de soja antes e após a interesterificação

\begin{tabular}{|c|c|c|c|c|}
\hline \multicolumn{5}{|c|}{ Dimensão fractal } \\
\hline & \multicolumn{4}{|c|}{ Temperatura $\left({ }^{\circ} \mathrm{C}\right)$} \\
\hline & 15 & 20 & 25 & 30 \\
\hline Banha:Soja & \multicolumn{4}{|c|}{ Antes da interesterificação } \\
\hline 100:0 & $1,60 \pm 0,01$ & $1,33 \pm 0,04$ & $1,59 \pm 0,01$ & $1,52 \pm 0,03$ \\
\hline $80: 20$ & $1,80 \pm 0,02$ & $1,21 \pm 0,05$ & $1,18 \pm 0,01$ & - \\
\hline $60: 40$ & $1,79 \pm 0,02$ & $1,21 \pm 0,03$ & $1,43 \pm 0,03$ & - \\
\hline Banha:Soja & \multicolumn{4}{|c|}{ Após a interesterificação } \\
\hline 100:0 & $1,49 \pm 0,02$ & $1,46 \pm 0,02$ & $1,60 \pm 0,02$ & $1,08 \pm 0,02$ \\
\hline $80: 20$ & $1,62 \pm 0,03$ & $1,27 \pm 0,04$ & $1,20 \pm 0,03$ & - \\
\hline $60: 40$ & $1,50 \pm 0,03$ & $1,10 \pm 0,01$ & $1,15 \pm 0,02$ & - \\
\hline
\end{tabular}

\section{CONCLUSÕES}

Com exceção da temperatura de $15^{\circ} \mathrm{C}$, ocorreu aumento do diâmetro e diminuição dos cristais à medida que aumentava a participação do óleo de soja na mistura.

As amostras interesterificadas apresentaram tendência à formação de cristais em menor número e de maior diâmetro que as originais às temperaturas de 15 e $20{ }^{\circ} \mathrm{C}$.

Como resultado prático, a cristalização da banha foi dificultada pelos efeitos da diluição e da interesterificação com o óleo de soja.

$\mathrm{O}$ diâmetro médio dos cristais de todas as amostras aumentou com o aumento da temperatura, atingindo valores da ordem de $200 \mu \mathrm{m}$.

\section{AGRADECIMENTOS}

À FAPESP, CAPES e CNPq, pelo apoio financeiro e bolsas concedidas aos autores.

\section{REFERÊNCIAS}

1. Lee, K. T.; Akoh, C. C.; J. Amer. Oil Chem. Soc. 1998, 75, 495.

2. Osborn, H. T.; Akoh, C. C.; Compr. Rev. Food Sci. Food Safety 2002, 3, 93
3. Gioielli, L. A. Em Entendendo a gordura: os ácidos graxos; Curi, R.; Pompéia, C.; Miyasaka, C. K.; Procopio, J., eds.; Manole: São Paulo, 2002, p. 457-465.

4. Hui, Y. H.; Bailey's industrial oil and fat products, $5^{\text {th }}$ ed., Wiley: New York, 1996, 2:603; 3:1

5. Willis, W. M.; Marangoni, A. G.; J. Am.. Oil Chem. Soc. 1999, 76, 443.

6. Willis, W. M.; Lencki, R. W.; Marangoni, A. G.; Critical Rev. Food Sci. Nutrition 1998, 38, 639 .

7. Narine, S. S.; Marangoni, A. G.; INFORM 1999, 10, 565.

8. Sato, K.; Chem. Eng. Sci. 2001, 56, 2255.

9. Herrera, M. L.; Falabella, C.; Melgarejo, M.; Añón, M. C.; J. Am. Oil Chem. Soc. 1998, 75, 1273

10. O'Brien, R. D.; Fats and oils - Formulating and processing for applications, Technomic: Basel, 1998, 7-10, 33-36, 98-108.

11. Simões, I. S.; Gioielli, L. A.; Óleos Grãos 1999, 50, 20.

12. Timms, R. E. Em Developments in oils and fats; Hamilton, R. J., ed.; Blackie: London, 1995, p. 204.

13. Marangoni, A. G.; Trends Food Sci Technol. 2002, 13, 37.

14. Wright, A. J.; Scanlon, M. G.; Hartel, R. W.; Marangoni, A. G.; J. Food Sci. 2001, 66, 1056

15. Larsson, K.; Lipids: Molecular organization, physical functions and technical applications, The Oil Press: Dundee, 1994, p.7.

16. Rousseau, D.; Hill, A. R.; Marangoni, A. G.; J. Am. Oil Chem. Soc. 1996 $73,973$.

17. Narine, S. S.; Marangoni, A. G.; Food Res. Intern. 1999, 32, 227.

18. Narine, S. S.; Marangoni, A. G.; Phys. Rev. E. 1999, 59, 1908.

19. Marangoni, A. G.; Hartel, R. W.; Food Technol. 1998, 52, 46.

20. Marangoni, A. G.; Rousseau, D.; J. Am. Oil Chem. Soc. 1996, 73, 991.

21. Narine, S. S.; Marangoni, A. G.; J. Cryst. Growth 1999, 198/199, 1315.

22. Wright, A. J.; Hartel, R. W.; Narine, S. S.; Marangoni, A. G.; J. Am. Oil Chem. Soc. 2000, 77, 463.

23. Silva, R.; C., Gioielli,; L. A. Rev. Bras. Ciênc. Farm. 2006, 42, 223.

24. Díaz Gamboa, O. W.; Gioielli, L. A.; Grasas Aceites 2003,54, 122.

25. Díaz Gamboa, O. W.; Gioielli, L. A.; Grasas Aceites 2003, 54, 161

26. Rodrigues, J. N.; Gioielli, L. A.; Food Res. Intern. 2003, 36, 149.

27. Simões, I. S.; Gioielli, L. A.; Rev. Bras. Ciênc. Farm. 1999, 35, 259.

28. Simões, I. S.; Gioielli, L. A.; Braz. Arch. Biol. Technol. 2000, 43, 241.

29. Sotero-Solis, V. E. S.; Gioielli, L. A.; Alimentaria 2001, 38, 131.

30. Marangoni, A. G.; Fat crystal networks. Marcel Dekker: New York, 2005.

31. Rodrigues, J. N.; Anton, C.; Gioielli, L. A.; Rev. Bras. Ciênc. Farm. 2003, 39, 93.

32. Stanley, D. W.; Aguilera, J. M.; Baker, K. W.; Jackman, R. L. Em Phase/ State transitions foods; Rao, M. A.; Hartel, R. W., eds.; Marcel Dekker: New York, 1998, p. 1-56.

33. Gioielli, L. A.; Simões, I. S.; Rodrigues, J. N.; J. Food Eng. 2003, 57, 347.

34. Rousseau, D.; Marangoni, A. G.; Jeffrey, K. R.; J. Am. Oil Chem. Soc. 1998, $75,1833$.

35. Gamboa, O. W. D.; Gioielli, L. A.; Quim. Nova 2006, 29, 646. 